\title{
Longitudinal music perception performance of postlingual deaf adults with cochlear implants using acoustic and/or electrical stimulation
}

\author{
Son A Chang ${ }^{1} \cdot$ Sujin Shin ${ }^{2, *} \cdot$ Sungkeong $\mathrm{Kim}^{3} \cdot$ Yeabitna Lee $^{3} \cdot$ \\ Eun Young Lee ${ }^{3} \cdot$ Hanee $\mathrm{Kim}^{4} \cdot$ You-Ree Shin $^{5} \cdot$ Young-Myoung Chun ${ }^{5, * *}$ \\ ${ }^{I}$ Soree Rehabilitation Center, Soree Ear Clinic, Graduate Program of Speech-Language Pathology, \\ Yonsei University College of Medicine, Seoul, Korea \\ ${ }^{2}$ Department of Communication Sciences and Disorders, University of Redlands, CA, USA \\ ${ }^{3}$ Soree Rehabilitation Center, Soree Ear Clinic, Seoul, Korea \\ ${ }^{4}$ Soree Rehabilitation West Center, Soree Ear Clinic, Seoul, Korea \\ ${ }^{5}$ Soree Ear Clinic, Seoul, Korea
}

\begin{abstract}
In this study, we investigated longitudinal music perception of adult cochlear implant (CI) users and how acoustic stimulation with CI affects their music performance. A total of 163 participants' data were analyzed retrospectively. 96 participants were using acoustic stimulation with $\mathrm{CI}$ and 67 participants were using electrical stimulation only via CI. The music performance (melody identification, appreciation, and satisfaction) data were collected pre-implantation, 1-year, and 2-year post-implantation. Mixed repeated measures of ANOVA and pairwise analysis adjusted by Tukey were used for the statistics. As result, in both groups, there were significant improvements in melody identification, music appreciation, and music satisfaction at 1-year, and 2-year post-implantation than a pre-implantation, but there was no significant difference between 1 and 2 years in any of the variables. Also, the group of acoustic stimulation with CI showed better perception skill of melody identification than the CI-only group. However, no differences found in music appreciation and satisfaction between the two groups, and possible explanations were discussed. In conclusion, acoustic and/or electrical hearing devices benefit the recipients in music performance over time. Although acoustic stimulation accompanied with electrical stimulation could benefit the recipients in terms of listening skills, those benefits may not extend to the subjective acceptance of music. These results suggest the need for improved sound processing mechanisms and music rehabilitation.
\end{abstract}

Keywords: music perception, music appreciation, music satisfaction, cochlear implant, electro-acoustic stimulation

\footnotetext{
*sujin_shin@redlands.edu, Corresponding author

**ymchunmd@hotmail.com, Corresponding author

Received 5 June 2021; Revised 12 June 2021; Accepted 12 June 2021

(c) Copyright 2021 Korean Society of Speech Sciences. This is an Open-Access article distributed under the terms of the Creative Commons Attribution NonCommercial License (http://creativecommons.org/licenses/by-nc/4.0) which permits unrestricted non-commercial use, distribution, and reproduction in any medium, provided the original work is properly cited.
} 


\section{Introduction}

Cochlear implant (CI) has been proven to deliver speech sounds successfully to the recipients with severe to profound hearing loss. Many studies have shown significantly improved speech perception scores after implantation (Chang et al., 2010; Dunn et al., 2014; Grieco-Calub \& Litovsky, 2010; Tyler et al., 2007).

However, the music perception of people with hearing loss is still significantly compromised even with high technology hearing devices such as CIs. Researchers reported that postlingually deafened CI users showed significantly reduced music perception skills. In daily life, music consists of integrated frequency, duration, and amplitude, which are regarded as primary acoustic features such as rhythm, pitch, and timbre, resulting in rapid ongoing changes in complexity (Hargreaves \& North, 2010; Yitao \& Li, 2013). Although CI has presented outstanding achievement on speech perception in quiet conditions and limited music perception in rhythmic contexts, CI users showed reduced accuracy in melody recognition and timbre (tone quality) recognition (Gfeller, 2016; Gfeller \& Lansing, 1991; Gfeller et al., 2006; Kang et al., 2009; Looi et al., 2012; McDermott \& Looi, 2004). For example, CI group recognized the timbre of the music only $36.7 \%$ correctly when their hearing counterparts recognized timbre $82.0 \%$ correctly (Wright \& Uchanski, 2012).

Also, patients with CIs have complained about the music listening experience through CIs in terms of appreciation and satisfaction. Many of them reported degraded music appreciation (Drennan et al., 2015; Migirov et al., 2009; Mirza et al., 2003). Mostly they feel uncomfortable with the sound quality and song lyrics perception during music listening (Collister \& Huron, 2008). For example, Mirza et al. (2003) reported that music appreciation scores dropped from 8.7 (out of 10) before implantation to 2.9 (out of 10) after implantation for postlingual CI users. Not only general music appreciation, but CI users also enjoyed timbre less than their hearing counterparts (Gfeller et al., 2003).

People listen to and enjoy music as a part of life. A communicative life is fulfilled with music and speech, so that the technologies should pursue the goals that aim to better perceive speech and music for the sake of people with hearing devices.

Current hearing technologies have agreed with this notion that they are heading to improve their devices to utilize the acoustic hearing essential to music perception and enjoyment. Residual hearing in low frequencies can provide elements of music such as formants, harmonics, and timbre. Regarding acoustic stimulation, there has been improvement in device type and functions in both CI and HA to utilize this information. Previous studies indicated that sounds through hearing devices with acoustic features could improve music perception and appreciation. Some of these researches compared music perception between CI users and hearing aid users (Looi et al., 2008), CI only users and bimodal (CI in one ear and HA in the other ear) users (Bae et al., 2019; Gantz et al., 2005; Gfeller et al., 2006; Kiefer et al., 2005; Kong et al., 2004; Looi \& She, 2010), or CI and electro-acoustic stimulation (EAS: electric stimulation and acoustic stimulation in the same ear) mechanism (Brockmeier et al., 2010; Gantz \& Turner, 2003, 2004).

These variations of acoustic stimulation accompanied with CI have been developed as the electrode arrays that are implanted into cochlea have evolved to preserve the existing structure. This technology resulted in preserving low-frequency perception after implantation, and more people with residual hearing pursue CI options when they experience communication difficulties with their hearing status. Thus, CI with low-frequency preservation needs a highly sophisticated surgery technique even there are good chances to be successful in hearing preservation after CI (Bae et al., 2019). Therefore, it is reasonable to follow up the long-term use of the devices to verify the devices' function for listening to music in their lives. However, acoustic use for the CI users has not been investigated in long-term perspectives, rarely focused on research.

This study investigated how adult users with various modes of hearing devices with $\mathrm{CI}$ adapted to their hearing status function in music listening performance. Research questions are as follow.

First, do participants with CI variation show improvement in music perception, appreciation, and satisfaction? If so, is there a long-term improvement after CI implantation? Second, do CI participants with acoustic stimulation show better music perception, appreciation, and satisfaction than participants with electrical stimulation exclusively?

\section{Methods}

\subsection{Participants}

The data of 163 adult CI recipients implanted at Soree Ear Clinic were analyzed retrospectively. The participants visited the clinic before and after implantation surgery to follow up performances. Their pre-implantation pure tone thresholds at 125, 250, 500, 750, $1 \mathrm{k}$, $1.5 \mathrm{k}, 2 \mathrm{k}, 3 \mathrm{k}, 4 \mathrm{k}$, and $6 \mathrm{kHz}$ were tested and musical perception test and musical appreciation and satisfaction questionnaires were done during their visits.

Participants were selected based on the following criteria; (1)17+ years old at the implantation, (2) one or two CI electrode arrays were implanted in their cochlea(s), (3) no detected anatomical abnormality on cochlea or cochlear nerve, (4) no diagnosed cognitive problems, (5) participated musical testes at least once at pre-implantation, 1-year, and 2-year post-implantation.

Then participants were divided into two groups based on their hearing device/stimulation types. If a participant gains hearing benefits through only electrical stimulation, he/she will be in CI group. The participants in this group utilize either unilateral CI (Uni-CI) or bilateral CI (Bi-CI) since CI provides only electrical stimulation. The other group (EAS group) consisted of adults who hear sounds not only electrical stimulation but also some type of acoustic stimulation. The acoustic options that this group has are $\mathrm{CI}$ in one ear and HA in the other ear (bimodal), EAS in one ear only (Uni-EAS), EAS in one ear and HA in the other ear (bimodal EAS), EAS in both ears (Bi-EAS), and EAS in one ear and CI in the other ear (Combined EAS).

The demographic information of the participants is summarized in Table 1.

\subsection{Procedures}

Participants were tested before the implantation and at their follow ups. In this study, we used data collected at pre-implantation, 1 year and 2 years after switch-on of the devices.

The music tests that the participants had were Melodic Contour Identification test (MCI; Galvin et al., 2007, 2009) and The Korean Version of Musical Background Questionnaire (KMBQ, An et al., 2019) which included appreciation and satisfaction questionnaires.

The MCI test was originally designed by Galvin et al. (2007) and 
Table 1. The demographic information of the participants

\begin{tabular}{|c|c|c|c|c|c|c|c|c|c|c|c|}
\hline \multicolumn{2}{|c|}{ Group } & \multicolumn{4}{|c|}{$\begin{array}{c}\text { CI users } \\
\text { (Uni-CI or Bi-CI) }\end{array}$} & \multicolumn{6}{|c|}{$\begin{array}{c}\text { EAS users } \\
\text { (Bimodal or EAS) }\end{array}$} \\
\hline \multirow{2}{*}{ Gender } & $\mathrm{M}$ & \multicolumn{4}{|c|}{35} & \multicolumn{6}{|c|}{41} \\
\hline & $\mathrm{F}$ & \multicolumn{4}{|c|}{32} & \multicolumn{6}{|c|}{55} \\
\hline \multirow{2}{*}{ Age } & Mean (yr) & \multicolumn{4}{|c|}{54} & \multicolumn{6}{|c|}{51} \\
\hline & $\mathrm{SD}(\mathrm{yr})$ & \multicolumn{4}{|c|}{16} & \multicolumn{6}{|c|}{16} \\
\hline \multirow[b]{2}{*}{$\begin{array}{c}\text { Duration of } \\
\text { deafness }\end{array}$} & Mean (yr) & \multicolumn{4}{|c|}{11.6} & \multicolumn{6}{|c|}{16.5} \\
\hline & $\mathrm{SD}(\mathrm{yr})$ & \multicolumn{4}{|c|}{$\begin{array}{c}12.1 \\
1 \text { progressive } \\
8 \text { unknown }\end{array}$} & \multicolumn{6}{|c|}{$\begin{array}{c}15.2 \\
3 \text { progressive } \\
10 \text { unknown }\end{array}$} \\
\hline \multirow{2}{*}{$\begin{array}{c}\text { Age at } \\
\text { implantation }\end{array}$} & Mean (yr) & \multicolumn{4}{|c|}{48.7} & \multicolumn{6}{|c|}{45.5} \\
\hline & $\mathrm{SD}(\mathrm{yr})$ & \multicolumn{4}{|c|}{16.2} & \multicolumn{6}{|c|}{6.2} \\
\hline Pre-op. PTA & Frequency $(\mathrm{Hz})$ & 125 & 250 & 500 & 750 & $1 \mathrm{k}$ & $1.5 \mathrm{k}$ & $2 \mathrm{k}$ & $3 \mathrm{k}$ & $4 \mathrm{k}$ & $6 \mathrm{k}$ \\
\hline CI group & \multirow{2}{*}{$\begin{array}{l}\text { Thresholds } \\
\text { (dB HL) }\end{array}$} & 82 & 89 & 95 & 104 & 103 & 113 & 105 & 108 & 108 & 111 \\
\hline EAS group & & 67 & 77 & 89 & 96 & 99 & 110 & 104 & 111 & 104 & 107 \\
\hline
\end{tabular}

CI, cochlear implant; Uni-CI, unilateral CI; Bi-CI, bilateral CI; EAS, electro-acoustic stimulation; Pre-op. PTA, pre-implantation pure tone audiometry.

modified to evaluate music perception, especially a melody identification in this study. The test was composed of 9 melodic patterns with 5 successive notes (Figure 1), and each interval between adjacent two notes was 2 semitones. The melodic patterns were randomly provided in three frequency ranges: 220-440, 440-880, and 880$1,760 \mathrm{~Hz}$. The musical stimuli were provided through a speaker at 75 $\mathrm{dB}$ SPL, and the participants were asked to select one of 9 patterns after listening to the stimuli. This test was implemented in auditiononly condition. After two rehearsals, the participants listened to a total of 27 musical patterns, three times of each of the nine patterns.



Figure 1. 9 patterns of Melody Contour Identification (MIC) tasks

KMBQ was developed based on the Iowa Musical Background Questionnaire (IMBQ) (An et al., 2019). KMBQ involves musical background and three factors of self-reported music perception. Musical background is related to previous musical experiences such as formal music education levels or personal music experiences. The first factor is satisfaction about listening to music and music enjoyment. The second and third factors contain self-reported music appreciation in music elements and sound quality related, which are embraced as music appreciation in this study. Each participant was asked to fill in the survey questions when they visited for the MCI test on a regular follow up session.

\section{Statistics (Method of analysis)}

Groups were divided based on their device types: CI group (Uni-CI or Bi-CI) and EAS group (Bimodal and/or EAS variation), and the testing time points were pre-implantation, 1-year, and 2-year postimplantation. To analyze the music perception, appreciation, and satisfaction of CI users over time between CI and EAS groups, a mixed-design (Group $\times$ Time) repeated measures analysis of variance (ANOVA) was used with music perception performance scores as dependent variables. Music perception performance were measured by MCI (melody identification) and KMBQ which includes music appreciation scores (quality of music and elements of music) and music satisfaction scores.

The main effect of the Group and Time conditions and the interaction between them were analyzed at the level of $p<0.05$. If there was a main effect of the Time, post-hoc analysis corrected by Tukey method was performed to determine where the difference happened among pre-implantation, 1-year, and 2-year post-implantation. Degrees of freedom was calculated using the Kenward-Roger method. All the statistical analyses were done using $\mathrm{R}$ program $(\mathrm{R}$ Core Team, 2020) and the lmerTest package (Kuznetsova et al., 2017).

\section{Results}

\subsection{Music perception improvement over time}

Mixed design repeated measures ANOVA showed significant main effects for the test periods on all music perception dependent variables, melody identification measured by MCI $[F(1,2)=35.81$, $\left.{ }^{* *} p<0.01\right]$, music appreciation scores including elements of music $\left[\mathrm{F}(1,2)=45.54, \quad{ }^{* *} p<0.01\right]$ and quality of music $[F(1,2)=25.01$, $\left.{ }^{* *} p<0.01\right]$, and music satisfaction scores $\left[F(1,2)=14.24,{ }^{* *} p<0.01\right]$. Pairwise analysis adjusted by Tukey for multiple comparison revealed that all the music performance scores improved between preimplantation and 1-year post-implantation (MCI: ${ }^{* *} p<0.01$, element of music: ${ }^{* *} p<0.01$, quality of music: ${ }^{* *} p<0.01$, music satisfaction: $\left.{ }^{* *} p<0.01\right)$ and pre-implantation and 2-year post- implantation (MCI: ${ }^{* *} p<0.01$, element of music: ${ }^{* *} p<0.01$, quality of music: ${ }^{* *} p<0.01$, music satisfaction: ${ }^{* *} p<0.01$ ) but there was no significant differences between 1-year and 2-year post-implantation (MCI: $p=0.98$, element 
of music: $p=0.35$, quality of music: $p=0.26$, music satisfaction: $p=0.42$ ). These results indicated that improved auditory input through both electrical signal only and electrical signal with acoustic stimulation enhanced music performance skills and experiences significantly compared to pre-implantation music perception abilities. However, the progress of improvement was not significantly continued between 1-year post-implantation and 2-year postimplantation. Table 2 presents the music performance results of both $\mathrm{CI}$ and EAS groups over time.

Table 2. Average (mean) and standard deviation (SD) of melody identification scores (MCI), music appreciation scores (Element of music, Quality of music) and music satisfaction scores at pre-implantation, 1-year post implantation, and 2-year post implantation for CI group and EAS group

\begin{tabular}{|c|c|c|c|c|c|c|c|}
\hline \multirow{3}{*}{\multicolumn{2}{|c|}{ Group }} & \multicolumn{6}{|c|}{ Time } \\
\hline & & \multicolumn{2}{|c|}{ Pre-surgery ${ }^{* *}$} & \multicolumn{2}{|c|}{1 -year post ${ }^{* *}$} & \multicolumn{2}{|c|}{2 -year post ${ }^{* *}$} \\
\hline & & mean & SD & mean & SD & mean & SD \\
\hline \multirow{2}{*}{ MCI } & EAS $^{* *}$ & 29.95 & 25.56 & 47.64 & 25.59 & 50.61 & 30.80 \\
\hline & $\mathrm{CI}^{* *}$ & 19.92 & 24.25 & 36.27 & 26 & 33.04 & 19.85 \\
\hline \multirow{2}{*}{$\begin{array}{l}\text { Element } \\
\text { of music }\end{array}$} & EAS & 45.17 & 16.99 & 57.78 & 20.27 & 64.83 & 17.42 \\
\hline & $\mathrm{CI}$ & 38.04 & 24.56 & 61.83 & 19.44 & 64.65 & 16.29 \\
\hline \multirow{2}{*}{$\begin{array}{l}\text { Quality } \\
\text { of music }\end{array}$} & EAS & 43.69 & 18.88 & 55.08 & 20.13 & 61.1 & 21.16 \\
\hline & $\mathrm{CI}$ & 38.42 & 24.44 & 55.92 & 20.64 & 62 & 22.43 \\
\hline \multirow{2}{*}{$\begin{array}{c}\text { Satisfaction } \\
\text { of music }\end{array}$} & EAS & 1.73 & 0.88 & 2.08 & 0.79 & 2.25 & 0.76 \\
\hline & CI & 1.42 & 0.75 & 1.97 & 0.75 & 2.31 & 0.83 \\
\hline
\end{tabular}

${ }^{* *} p<0.01$.

EAS, electro-acoustic stimulation; CI, Cochlear implant.

\subsection{Acoustic advantages in music performance}

The main effects of the Group (CI group and EAS group) were analyzed to examine the advantages of acoustic hearing to the electrical stimulation compared to only electrical hearing. Mixed design repeated measures ANOVA showed a significant main effect of Group when the dependent variable was music perception skill measured by MCI $\left[F(1,2)=7.61,{ }^{* *} p<0.01\right]$, suggesting that acoustic input benefits music perception skills than exclusively electrical stimulation. However, there was no statistically significant main effects of Group on music appreciation scores [element of music: $F(1$, $2)=0.34, p=0.55$, quality of music: $F(1,2)=0.45, p=0.50]$ and music satisfaction scores $[F(1,2)=1.42, p=0.23]$. These results indicated that the benefit of acoustic auditory input does not expand to music experience, although participants improved the skill to listen to the music (Figure 2).



Figure 2. Average scores and standard errors of melody identification scores (MCI), music appreciation scores (Element of music, Quality of music) and music satisfaction scores at pre-implantation, 1-year post-implantation, and 2-year post-implantation for EAS group and CI group. CI, Cochlear implant; EAS, electro-acoustic stimulation.

\section{Discussion}

In the current study, after one year of device use, both CI and EAS groups showed significant improvement in music perception from the pre-implant period measured by melody identification, appreciation of elements and quality of music, and satisfaction about music. Music performance changes longitudinally, which, unfortunately, few researches have explored. Our data suggested that both CI and EAS users significantly improved their music listening abilities in all three categories of music performance compared to the pre-implantation status. The results are expanding our knowledge of music ability changes over time and encouraging results that improvement maintained up to 2 years.

It is an exciting result supporting that current CI system using electrical stimulation only has improved in music perception unlike previous studies showing degraded music perception after implantation (Gfeller, 2016; Gfeller et al., 2006; Kang et al., 2009; Looi et al., 2012). This might be because the previous studies did not follow the performance long enough for the participants to adapt and utilize the new signals that they gotten through CI system.

It is also an evidence that EAS group did not lose their residual hearing after the electrode implantation as least for 2 years. It had been known that CI surgery technique resulted in a total loss of residual hearing. Evolved electrode manufacturing and advanced surgical technique (Bae et al., 2019) could reserve the low frequency residual hearing for the $\mathrm{CI}$ recipients to attain better music perception 
in this study.

Our current study explored music results between pre-implant, 1-year and 2-year post-implantation and found significant improvement between pre and post implantation, however the difference between 1 and 2-year post-implantation was not significant. These results also can be compared with speech perception improvement over time in CI users. Chang et al. (2010) reported the same pattern in speech that showed significant improvement after 1-year postimplantation in monosyllable word scores from the pre-implant period and then plateaued afterward up to 6-year post-implantation. Based on this research, one can suspect music perception may be also plateaued after 1 year, however, we do not have enough research evidence for that now. In the future, our observation can be extended further to exam if this improvement maintains for more years or if there is further improvement after two years of implant experience.

However, still, many implantees have experienced hearing drops after surgery. We also observed some CI recipients went through hard time to adapt to the sounds by the hybrid system using electrical and acoustic stimulation even with the residual hearing. It seems that they overcame the difficulty adjusting to the new sounds after one-year of device use. Further study is needed to see how this recovery curve is drawn after implantation and if music therapy can be a help of this happening.

The following interesting finding of this study is that the EAS group using electrical stimulation accompanied with acoustic stimulation via their hearing devices scored better in melody identification than the CI group using exclusively electrical sound processing. It means that they could receive better spectral resolution through their acoustic device utilizing low-frequency sounds with their residual hearing.

Hearing technologies have developed to stimulate the human auditory system via direct electrical stimulation on an auditory nerve by CI devices; simultaneously, acoustic amplification systems have evolved to attain better hearing perception through air conduction sound delivery when recipients have a usable residual hearing. This study showed that current hearing technologies combine these two different sound conduction systems with improving hearing abilities and the quality of the incoming sounds.

In accordance with our study, prior work has documented the benefit of acoustic input on music perception and appreciation in hearing device users with severe to profound hearing loss (Gantz et al., 2005; Kiefer et al., 2005; Kong et al., 2004; Looi \& She, 2010). These acoustic benefits suggest improving the music listening experience for listeners with bimodal device or EAS device types. For example, Looi \& She (2010) reported that listening with bimodal use could improve the melody identification and quality of music in the questionnaire they developed.

However, unlike Looi \& She (2010), the current finding did not support acoustic benefits to music appreciation and satisfaction over the CI group. One of the possible explanations could be the level of expectation. In our study, EAS group participants demonstrated greater music perception scores before the surgery compared to the CI group participants due to their residual hearing. Although the EAS group improved music perception scores more than the CI group, the EAS group's expectation could have been higher for listening to music than the CI group, and that might lead to similar music appreciation and satisfaction scores for both groups even though the acoustic group had greater improvement in music perception test. Another possible explanation could be mismatched auditory feedback.
While the CI group only hears through one type of auditory feedback, the EAS group receives acoustic and electrical stimulation. Therefore, a mismatch of timing and different input sound quality may discourage appreciation and satisfaction, not to the level of their music perception skills. However, these explanations need further investigation.

It has also been known that there is a discrepancy between perception skills and subjective experiences in the CI users in terms of music. Many studies found that CI users showed improved perception skills, including melody (Galvin et al., 2009; Nakata et al., 2005; Xu et al., 2009; Yuba et al., 2009) and timbre (Gfeller et al., 2003, Looi $\&$ She, 2010), but not appreciation and satisfaction about music after implantation (Wright \& Uchanski, 2012).

In this study, we divided the participant groups by the presence of acoustic stimulation. It provided important implications to hearing preservation and acoustic amplification. However, also it was challenging because acoustic stimulation can come in many different forms as the acoustic options vary, such as bimodal, Uni-EAS, bimodal EAS, Bi-EAS, Combined EAS, and that made the choice of device more complicated.

Even though these results suggested the possibilities of better music perception and appreciation through acoustic features, device choices are more complicated when applied to real clinical situations. EAS users may change their mapping system to only electrical stimulation sometimes to try out, and vice versa would happen to CI patients. Yoon et al. (2019) suggested optimal mapping strategies to maximize acoustic benefit along with electrical sound processing. Research that explores music performance of EAS users who use some acoustic input to their implants is needed according to the residual hearing they reserve in their cochlea and mapping strategies to provide overall acoustic benefit to implantation.

In the future, researchers will be able to analyze the effect of specific types of device combinations on music listening. Also, some of the participants tried acoustic stimulation during electrical stimulation and/or changed their stimulation mode, which we could not include in the data points. Further analysis can explore how these temporary or permanent device type changes affect music perception, appreciation, and satisfaction. We explored this benefit would expand to any device types and combinations providing acoustic input to implant users.

The findings and discussions of the current study may lead to the need of music rehabilitation to adult CI users. Our data showed a high standard deviation for music perception, appreciation, and satisfaction scores, which may imply the possibility of improving with music rehabilitation. Music rehabilitation might be helpful to adjust postimplant expectations on music listening, which was discussed as one of the possible reasons for no group differences. Music therapists would be able to educate the way of listening and interpreting new signals from their devices to improve their music performance.

\section{Conclusion}

Music perception performance was improved in all areas, music perception, appreciation, and satisfaction, after implantation, and it maintained for up to two years. The results suggested the help of electro-acoustic stimulation improve melody identification skills more than electrical stimulation only, although music appreciation and satisfaction of the participants were not improved. These findings can 
be applied to future device selections and the need for music rehabilitation for this population.

\section{References}

An, Y. H., Choi, B. Y., Kim, J. B., Choi, J. W., Park, M. K., Han, G. C., Cheon, B. C., ․ Cho, Y. S. (2019). Translation and linguistic validation of Korean version of musical background questionnaire. Korean Society of Otorhinolaryngology-Head and Neck Surgery, 62(12), 686-698.

Bae, S. C., Shin, Y. R., \& Chun, Y. M. (2019). Cochlear implant surgery through round window approach is always possible. Annals of Otology, Rhinology, and Laryngology, 128(suppl. 6), 38S-44S.

Brockmeier, S. J., Peterreins, M., Lorens, A., Vermeire, K., Helbig, S., Anderson, I., Skarzynski, H., ․ Kiefer, J. (2010). Music perception in electric acoustic stimulation users as assessed by the Mu. SIC test. In P. van de Heyning, \& A. K. Punte (Eds.), Cochlear implants and hearing preservation (Vol. 67, pp. 70-80). Berlin, Germany: Karger Publishers.

Chang, S., Tyler, R. S., Dunn, C. C., Ji, H., Witt, S. A., Gantz, B., \& Hansen, M. (2010). Performance over time on adults with simultaneous bilateral cochlear implants. Journal of the American Academy of Audiology, 21(1), 35-43.

Collister, L. B., \& Huron, D. (2008). Comparison of word intelligibility in spoken and sung phrases. Empirical Musicology Review, 3(3), 109-125.

Drennan, W. R., Oleson, J. J., Gfeller, K., Crosson, J., Driscoll, V. D., Won, J. H., Elizabeth, S. A., \& Rubinstein, J. T. (2015). Clinical evaluation of music perception, appraisal and experience in cochlear implant users. International Journal of Audiology, 54(2), 114-123.

Dunn, C. C., Walker, E. A., Oleson, J., Kenworthy, M., Van Voorst, T., Tomblin, J. B., Haihong, J., ‥ Gantz, B. J. (2014). Longitudinal speech perception and language performance in pediatric cochlear implant users: the effect of age of implantation. Ear and Hearing, 35(2), 148-160.

Galvin, J. J., III, Fu, Q. J., \& Nogaki, G. (2007). Melodic contour identification by cochlear implant listeners. Ear and Hearing, 28(3), 302.

Galvin, J. J., III, Fu, Q. J., \& Shannon, R. V. (2009). Melodic contour identification and music perception by cochlear implant users. Annals of the New York Academy of Sciences, 1169(1), 518-533.

Gantz, B. J., \& Turner, C. W. (2003). Combining acoustic and electrical hearing. The Laryngoscope, 113(10), 1726-1730.

Gantz, B. J., \& Turner, C. (2004). Combining acoustic and electrical speech processing: Iowa/Nucleus hybrid implant. Acta Otolaryngologica, 124(4), 344-347.

Gantz, B. J., Turner, C., Gfeller, K. E., \& Lowder, M. W. (2005). Preservation of hearing in cochlear implant surgery: advantages of combined electrical and acoustical speech processing. The Laryngoscope, 115(5), 796-802.

Gfeller, K. (2016). Music-based training for pediatric CI recipients: a systematic analysis of published studies. European Annals of Oto-rhino-laryngology, Head and Neck Diseases, 133(Suppl. 1), S50-S56.

Gfeller, K., \& Lansing, C. R. (1991). Melodic, rhythmic, and timbral perception of adult cochlear implant users. Journal of Speech,
Language, and Hearing Research, 34(4), 916-920.

Gfeller, K., Christ, A., Knutson, J., Witt, S., \& Mehr, M. (2003). The effects of familiarity and complexity on appraisal of complex songs by cochlear implant recipients and normal hearing adults. Journal of Music Therapy, 40(2), 78-112.

Gfeller, K. E., Olszewski, C., Turner, C., Gantz, B., \& Oleson, J. (2006). Music perception with cochlear implants and residual hearing. Audiology and Neurotology, 11(Suppl. 1), S12-S15.

Grieco-Calub, T. M., \& Litovsky, R. Y. (2010). Sound localization skills in children who use bilateral cochlear implants and in children with normal acoustic hearing. Ear and Hearing, 31(5), 645-656.

Hargreaves, D. J., \& North, A. C. (2010). Experimental aesthetics and liking for music. In P. N. Juslin, \& J. A. Sloboda (Eds.), Handbook of music and emotion: Theory, research, and applications (pp. 515-546). Oxford, UK: Oxford University Press.

Kang, R., Nimmons, G. L., Drennan, W., Longnion, J., Ruffin, C., Nie, K., Won, J. H., ․ Rubinstein, J. (2009). Development and validation of the University of Washington Clinical Assessment of Music Perception test. Ear and Hearing, 30(4), 411-418.

Kiefer, J., Pok, M., Adunka, O., Stürzebecher, E., Baumgartner, W., Schmidt, M., Tillein, J., ․ Gstoettner, W. (2005). Combined electric and acoustic stimulation of the auditory system: results of a clinical study. Audiology and Neurotology, 10(3), 134-144.

Kong, Y. Y., Cruz, R., Jones, J. A., \& Zeng, F. G. (2004). Music perception with temporal cues in acoustic and electric hearing. Ear and Hearing, 25(2), 173-185.

Kuznetsova, A., Brockhoff, P. B., \& Christensen, R. H. B. (2017). lmerTest package: tests in linear mixed effects models. Journal of Statistical Software, 82(13), 1-26.

Looi, V., Gfeller, K., \& Driscoll, V. D. (2012). Music appreciation and training for cochlear implant recipients: a review. Seminars in Hearing, 33(4), 307-334.

Looi, V., McDermott, H., McKay, C., \& Louise, H. (2008). Music perception of cochlear implant users compared with that of hearing aid users. Ear and Hearing, 29(3), 421-434.

Looi, V., \& She, J. (2010). Music perception of cochlear implant users: a questionnaire, and its implications for a music training program. International Journal of Audiology, 49(2), 116-128.

McDermott, H. J., \& Looi, V. (2004). Perception of complex signals, including musical sounds, with cochlear implants. International Congress Series, 1273, 201-204.

Migirov, L., Dagan, E., \& Kronenberg, J. (2009). Surgical and medical complications in different cochlear implant devices. Acta Oto-Laryngologica, 129(7), 741-744.

Mirza, S., Douglas, S. A., Lindsey, P., Hildreth, T., \& Hawthorne, M. (2003). Appreciation of music in adult patients with cochlear implants: a patient questionnaire. Cochlear Implants International, $4(2), 85-95$.

Nakata, T., Trehub, S. E., Mitani, C., Kanda, Y., Shibasaki, A., \& Schellenberg, E. G. (2005). Music recognition by Japanese children with cochlear implants. Journal of Physiological Anthropology and Applied Human Science, 24(1), 29-32.

R Core Team (2020). R: A language and environment for statistical computing. [Computer software]. Vienna, Austria: R Foundation for Statistical Computing. Retrieved from https://www.R-pro ject.org/

Tyler, R. S., Dunn, C. C., Witt, S. A., \& Noble, W. G. (2007). Speech perception and localization with adults with bilateral sequential 
cochlear implants. Ear and Hearing, 28(2), 86S-90S.

Wright, R., \& Uchanski, R. M. (2012). Music perception and appraisal: cochlear implant users and simulated cochlear implant listening. Journal of the American Academy of Audiology, 23(5), 350-365.

Xu, L., Zhou, N., Chen, X., Li, Y., Schultz, H. M., Zhao, X., \& Han, D. (2009). Vocal singing by prelingually-deafened children with cochlear implants. Hearing Research, 255(1-2), 129-134.

Yitao, M., \& Li, X. (2013). Music and cochlear implants. Journal of Otolaryngology, 8(1), 32-38.

Yoon, Y. S., Shin, Y. R., Kim, J. M., Coltisor, A., \& Chun, Y. M. (2019). Optimizing maps for electric acoustic stimulation users. Cochlear Implants International, 20(3), 106-115.

Yuba, T., Itoh, T., \& Kaga, K. (2009). Unique technological voice method (the YUBA method) shows clear improvement in patients with cochlear implants in singing. Journal of Voice, 23(1), 119-124.

\section{- Son A Chang}

Director, Visiting Professor, Soree Rehabilitation Center, Soree Ear Clinic

Graduate Program of Speech-Language Pathology, Yonsei University College of Medicine

592 Cheonho-daero Gwangiin-gu, Seoul 04986, Korea

Tel: +82-70-4881-4874

Email: sachang@yonsei.ac.kr

Areas of interest: Cochlear implant, Speech perception,

Rehabilitation for the people with hearing loss, Auditory-verbal therapy

- Sujin Shin, Corresponding author

Assistant Professor, Truesdail Center for Communication

Sciences and Disorders

University of Redlands, 1200 E Colton Avenue, Redlands, CA, 92374, USA

Tel: +1-909-748-8552

Email: sujin_shin@redlands.edu

Areas of interest: Effect of auditory feedback on speech pro-

duction and language development, oral rehabilitation

\section{- Sungkeong Kim}

Music Therapist, Soree Rehabilitation Center, Soree Ear Clinic

529 Cheonho-daero, Gwangjin-gu, Seoul 04986, Korea

Tel: +82-2-1600-7592

Email: lightsaltsk@gmail.com

Areas of interest: Music rehabilitation, Musical behavior,

Hearing-impairments, Cochlear implant

\section{- Yeabitna Lee}

Music Therapist, Soree Rehabilitation Center, Soree Ear Clinic

529 Cheonho-daero, Gwangjin-gu, Seoul 04986, Korea
Tel: +82-2-1600-7592

Email: twinkleemt@gmail.com

Areas of interest: Music rehabilitation, Hearing-impairments, Cochlear implant

\section{- Eun Young Lee}

Music Therapist, Soree Rehabilitation Center, Soree Ear Clinic 592 Cheonho-daero Gwangin-gu, Seoul 04986, Korea

Tel: +82-2-1600-7592

Email: eleemt@gmail.com

Areas of interest: Hearing impairment, Cochlear implant, Music re/habilitation, Pediatrics

\section{- Hanee Kim}

Music Therapist, Soree Rehabilitation West Center, Soree Ear Clinic

307, Gangseo-ro, Gangseo-gu, Seoul 07632, Korea

Tel: $+82-2-1600-7592$

Email: jxluvu@naver.com

Areas of interest: Music rehabilitation, Hearing impairment, Cochlear implant

\section{- You-Ree Shin}

Medical Doctor, Soree Ear Clinic

592 Cheonho-daero Gwangjin-gu, Seoul 04986, Korea

Tel: +82-2-1600-7592

Email: newglassent@naver.com

Areas of interest: Ear surgery, Cochlear implant, Hearing aids

- Young-Myoung Chun, Corresponding author

Representative, Medical Doctor, Soree Ear Clinic

592 Cheonho-daero Gwangjin-gu, Seoul 04986, Korea

Tel: +82-2-1600-7592

Email: ymchunmd@hotmail.com

Areas of interest: Ear surgery, Cochlear implant, Tinnitus 